\title{
The Lure of Bones
}

I was looking at bones during a histology class in medical school at the University of Oslo, and I thought they were very beautiful. I decided I wanted to study prehistoric bones in Africa but would first need to know how to do scientific research.

So I took two years off from medical school to study bone collagen using the electron microscope. The institute I was in focused on neurology, so I was told I would have to conduct my studies on my own.

I published six papers as a single author and obtained my Ph.D. The drive to do research came entirely from within, but the institute was very supportive. The head of the institute obtained a grant to support my research and to buy the materials and equipment I needed. Had it not been for that, my career might not have turned out the way it did.

I received my M.D and Ph.D. degrees in 1967, and I was then faced with a choice: did I want to treat one patient at a time or do something that could potentially benefit many more people? I chose the second option. I have taken this choice very seriously, and it flavors my view of scientific research. I think science is fun and exciting, but it is not a game.

I do get easily excited, especially about questions for which there are no answers, but at the back of my mind is always the medical question. I think about how the science we are doing will improve the basis for diagnosis and treatment of disease.

Since my student days, my research interest has been the extracellular matrix. I have been studying its role in skeletal and vascular development and disorders using different techniques. To be successful in science, you need to focus on the most important questions in biology and then address them with the most powerful tools available. I have seen scientists get pushed to the sidelines because they could not adapt their methods.

Of course I want to make important contributions to specific projects and papers, but as I get older I am realizing another valuable contribution is to leave a legacy. When I look at the number of people who have passed through my lab and what they have accomplished, I feel good about what I have done. Some of my former students and postdocs are now collaborators, while others have become competitors, which is great too. It means they have been successful.

I try to be very open. I tell my students that they should not be afraid to talk about a result or present the latest finding at a meeting for fear that someone might steal their ideas. Sometimes this is risky, but overall it is the best philosophy. Being open leads to the best collaborations and, in the end, the best science. But I tend to be a very optimistic person, and I think that in the end everything always works out.

One of the latest challenges I have taken on is to become the editor-in-chief of the Journal of Negative Results in Biomedicine, which made its debut in February of last year. My involvement with the journal was prompted by a visit from a German medical student, Christian Pfeffer, who had an idea for a journal that would publish negative data. I thought this was a good idea. I had thought myself about how results that are regarded as negative do not get the press they deserve.

Results are negative only in the context of what people think is important. Scientists, reviewers, and journal editors favor findings that extend what we think we know already. If a result is contrary to what we think, we tend to be skeptical. As a result, these types of data do not make it into traditional journals.

When I am not working or spending time with my family, I like to garden. I do my best thinking when I am on all fours in the dirt. Right now I spend one hour every morning in the garden weeding. I have been having a long-standing fight with Bishop weed, but I might have the upper hand. I am now trying a combined physical removal and chemical approach.

As told to Laura Bonetta, a science writer based in Bethesda, MD. 